\title{
Dietary Magnesium and Kidney Function Decline: The Healthy Aging in Neighborhoods of Diversity across the Life Span Study
}

\author{
Casey M. Rebholz ${ }^{a, b} \quad$ Adrienne Tin $^{a, b} \quad$ Yang Liu $^{c} \quad$ Marie Fanelli Kuczmarski ${ }^{\mathrm{e}}$ \\ Michele K. Evans ${ }^{d}$ Alan B. Zonderman ${ }^{d}$ Deidra C. Crews ${ }^{\text {b, c }}$ \\ ${ }^{a}$ Department of Epidemiology, Johns Hopkins Bloomberg School of Public Health, ${ }^{b}$ Welch Center for Prevention, \\ Epidemiology, and Clinical Research, Johns Hopkins University, ' Division of Nephrology, Department of \\ Medicine, Johns Hopkins University School of Medicine, and d Laboratory of Epidemiology and Population \\ Sciences, National Institute of Aging, National Institutes of Health, Baltimore, Md., and e Department of \\ Behavioral Health and Nutrition, College of Health Sciences, University of Delaware, Newark, Del., USA
}

\section{Key Words}

Diet - Glomerular filtration rate $\cdot$ Healthy Aging in Neighborhoods of Diversity across the Life Span . Kidney disease $\cdot$ Magnesium $\cdot$ Primary prevention

\begin{abstract}
Background: Prior studies suggest that certain aspects of the diet related to magnesium intake, such as dietary acid load, protein intake and dietary patterns rich in fruits and vegetables, may impact kidney disease risk. We hypothesized that lower dietary magnesium intake would be prospectively associated with more rapid kidney function decline. Methods: Among participants in the Healthy Aging in Neighborhoods of Diversity across the Life Span study with estimated glomerular filtration rate (eGFR) $\geq 60 \mathrm{ml} /$ $\mathrm{min} / 1.73 \mathrm{~m}^{2}$ at baseline (2004-2009), dietary magnesium intake was calculated from two 24 -hour dietary recalls. Rapid decline was defined as $\geq 3 \%$ eGFR decline per year. Results: Median (25th-75th percentile) dietary magnesium intake was 116 (96-356) mg/1,000 kcal. Among 1,252 participants,
\end{abstract}

those with lower dietary magnesium intake were younger, and were more likely to be African-American men. A total of 177 participants (14.1\%) experienced rapid eGFR decline over a median follow-up of 5 years. Lower dietary magnesium intake was significantly associated with a greater odds of rapid eGFR decline (OR for tertile 1 vs. $3: 2.02,95 \% \mathrm{Cl} 1.05-$ $3.86, \mathrm{p}$ value for trend across tertiles $=0.02$ ) in analyses adjusted for sociodemographics (age, sex, race, education level, health insurance status, poverty status), kidney disease risk factors (smoking status, diabetes, hemoglobin A1c, hypertension, body mass index), baseline eGFR and dietary factors (total energy intake; diet quality; dietary intake of fiber, sodium, calcium, potassium and phosphorus). Conclusions: In this urban population, lower dietary magnesium intake was independently associated with greater odds of rapid kidney function decline.

(c) 2016 S. Karger AG, Base

\section{KARGER}

E-Mail karger@karger.com www.karger.com/ajn
2016 S. Karger AG, Basel

0250-8095/16/0445-0381\$39.50/0
Casey M. Rebholz

Department of Epidemiology

Johns Hopkins Bloomberg School of Public Health

2024 East Monument Street, Suite 2-600, Baltimore, MD 21287 (USA)

E-Mail crebhol1@jhu.edu 


\section{Introduction}

Chronic kidney disease (CKD) is a major public health issue. It affects approximately $13 \%$ of adults in the US and is a strong risk factor for progression to end-stage renal disease, cardiovascular disease and mortality [1-4]. Unfortunately, prevention and treatment options for CKD and end-stage renal disease are limited [5]. Identifying novel risk factors for CKD may increase our understanding of the pathogenesis of CKD and reveal insights for prevention strategies.

Low level of magnesium in the blood has recently been shown to be a novel risk factor for incident CKD and incident end-stage renal disease $[6,7]$. Among individuals with existing kidney disease, low blood magnesium levels may increase the risk of progression to end-stage renal disease, cardiovascular disease and allcause mortality [8-10]. Prior studies suggest that certain aspects of the diet related to magnesium, such as dietary acid load, dietary intake of protein from vegetable sources and the Dietary Approaches to Stop Hypertension (DASH) dietary pattern, may impact kidney disease risk [11-14]. However, little is known about the relation of dietary intake of magnesium with kidney disease risk.

To inform future efforts to prevent CKD and its associated adverse health consequences, the objective of this study was to determine whether low dietary magnesium intake was prospectively associated with change in kidney function in the Healthy Aging in Neighborhoods of Diversity across the Life Span (HANDLS) study, a cohort of African-American and Caucasian, adult men and women residing in Baltimore, Maryland.

\section{Methods}

\section{Study Design}

The HANDLS study is a population-based, prospective cohort study, which was initiated to examine the influence and interaction of race and socioeconomic status on cardiovascular and cerebrovascular health among racial minority and lower socioeconomic population subgroups. The study design has been previously described [15]. Briefly, city-dwelling, African-American and Caucasian men and women aged 30-64 years were recruited from 12 neighborhoods in Baltimore, Maryland, that reflect socioeconomic and racial diversity. A total of 3,720 participants enrolled in the HANDLS study between August 2004 and March 2009 (wave 1; baseline for the present study). Follow-up study visits were planned at 3-4 year intervals. The first (partial) follow-up visit occurred in April 2006-October 2011 (wave 2), and the second (complete) follow-up visit occurred in June 2009-July 2013 (wave 3). Study participants provided written documentation of informed consent.
Procedures were followed in accordance with ethical guidelines for human studies and the study protocol was approved by the institutional review board.

\section{Study Population}

In the present study, we included participants with serum creatinine measured at wave 1 using isotope-dilute mass spectrometry (IDMS), the recommended method for creatinine assay ( $\mathrm{n}=$ $2,517)[16]$. Then, we excluded participants with baseline estimated glomerular filtration rate $(\mathrm{eGFR})<60 \mathrm{ml} / \mathrm{min} / 1.73 \mathrm{~m}^{2}(\mathrm{n}=131)$, those with missing dietary intake data $(n=587)$, those without measurements of serum creatinine at the wave 3 follow-up study visit $(n=473)$ and those with missing information on covariates $(\mathrm{n}=74)$. After these exclusions, the analytic study population consisted of 1,252 HANDLS study participants. Study participants who were included were similar to those who were excluded on the basis of mean age ( 47 vs. 48 years, respectively; $p=0.14$ ), AfricanAmerican race ( 57 vs. $60 \%$, respectively; $\mathrm{p}=0.07$ ) and mean body mass index ( 30 vs. $30 \mathrm{~kg} / \mathrm{m}^{2}$, respectively; $\mathrm{p}=0.66$ ), but differed on the basis of male sex ( 41 vs. $48 \%$, respectively; $p<0.001$ ), current smoking status ( 44 vs. $53 \%$, respectively; $\mathrm{p}<0.001$ ) and health insurance ( 69 vs. $65 \%$, respectively; $\mathrm{p}=0.03$ ).

\section{Measurement of Dietary Intake}

Dietary intake was assessed using two 24-hour dietary recalls which were administered by trained interviewers using the US Department of Agriculture's Automatic Multiple Pass Method (AMPM; versions 2.3-2.6) [17-19]. This dietary assessment instrument included illustrations of portion sizes to improve the accuracy of the quantity of food consumed. The first dietary recall was administered during a household interview, and the second dietary recall was administered 7-10 days later in a mobile research vehicle. Food items were coded using Survey Net and linked to the Food and Nutrient Database for Dietary Studies version 3.0 to estimate nutrient intake. The average of the 2 estimated values of nutrient intake (magnesium, calcium, potassium, phosphate, sodium, fiber, total energy intake) based on the two 24-hour dietary recalls was used in the analysis. For this analysis, we categorized dietary intake of magnesium per 1,000 kcal by tertiles of the distribution, as most participants were below the recommended daily allowance $(400-420 \mathrm{mg} /$ day for men and $310-320 \mathrm{mg} /$ day for women) [20]. Diet quality was assessed using the Healthy Eating Index-2010 score, which is comprised of 12 components: total fruit, whole fruit, total vegetables, greens and beans, whole grains, dairy, total protein foods, seafood and plant proteins, fatty acids, refined grains, sodium and empty calories [21]. Scores range from 0 to 100 , with 100 representing optimal diet quality.

\section{Ascertainment of Rapid eGFR Decline}

Serum creatinine for included participants was measured by Quest Diagnostics, Inc. using IDMS and standardized to the reference laboratory at the Cleveland Clinic (Olympus America, Inc., Melville, N.Y., USA). eGFR was calculated using the CKD Epidemiology Collaboration equation based on serum creatinine at baseline (2004-2009) and the wave 3 follow-up study visit (2009-2013) [22]. The outcome of interest was rapid eGFR decline defined as $\geq 3 \%$ eGFR decline per year, which has been used in previously published studies $[23,24]$. The time interval for the denominator of rate of eGFR decline was calculated as the difference between the date of the baseline study visit and the date of the wave 3 follow-up study visit. 
Assessment of Other Variables

The baseline (wave 1) study visit consisted of 2 phases. Phase 1 took place during a household visit and involved a survey administered by trained interviewers to collect information on sociodemographics (age, sex, race, educational level), health behaviors (smoking status), household income, health insurance status and other relevant participant characteristics. Phase 2 took place in the mobile research vehicle and consisted of the following: (1) a physical examination to measure blood pressure, body weight and height; and (2) medical history to ascertain information on diagnosed disease (diabetes, hypertension) and medication use. Fasting blood specimens were collected for the measurement of glucose, hemoglobin A1c (HbA1c), creatinine and other measures of health status.

Hypertension was defined as an average of seated and standing systolic blood pressure $\geq 140 \mathrm{~mm} \mathrm{Hg}$, an average of seated and standing diastolic blood pressure $\geq 90 \mathrm{~mm} \mathrm{Hg}$, a history of blood pressure medication use or a self-report of diagnosed hypertension. Diabetes mellitus was defined as fasting plasma glucose concentration $\geq 126 \mathrm{mg} / \mathrm{dl}$ or self-report of diagnosed diabetes. Poverty status was defined as self-reported household annual income $<125 \%$ of the 2004 US Department of Health and Human Services poverty guidelines [25].

\section{Statistical Analysis}

Baseline characteristics of participants were reported using descriptive statistics and compared by tertiles of dietary magnesium intake using Wilcoxon rank sum tests for skewed continuous variables (education level and HbA1c), t tests for non-skewed continuous variables and $\chi^{2}$ tests for categorical variables. The association between dietary magnesium intake and rapid eGFR decline was evaluated using logistic regression to estimate ORs and 95\% CIs in a series of models. Model 1 evaluated the unadjusted association between tertiles of dietary magnesium intake (using tertile 3 as the reference group) and rapid decline in eGFR. Model 2 was adjusted for sociodemographic factors (age, sex, race, education level, health insurance status, poverty status), history of smoking and total energy intake. Model 3 included the covariates in model 2 and added baseline eGFR. Finally, model 4 additionally adjusted for hypertension, diabetes, body mass index, $\mathrm{HbA1c}$, diet quality and other dietary intake variables (fiber, sodium, calcium, potassium, phosphate). The $\mathrm{p}$ value for trend was obtained by using the tertiles of dietary magnesium intake per $1,000 \mathrm{kcal}$ as a continuous variable. We also examined potential effect modification of the association between dietary magnesium intake and rapid kidney function decline by race, sex, diabetes, hypertension status and poverty status.

\section{Results}

At baseline, the study population had a mean age of 47 years, $57 \%$ were African-American, and $41 \%$ were male. The mean baseline eGFR in the overall study population was $97 \mathrm{ml} / \mathrm{min} / 1.73 \mathrm{~m}^{2}$. Median (25th-75th percentile) dietary magnesium intake was 116 (96-356) $\mathrm{mg} / 1,000 \mathrm{kcal}$.

Dietary Magnesium and eGFR Decline
Those with lower dietary magnesium intake (tertile 1 vs. 3) were significantly younger (mean age 46 vs. 49 years), more likely to be African-American (66 vs. $47 \%$ ) and male (46 vs. $32 \%$ ), more likely to be living in poverty (44 vs. $27 \%$ ) and less likely to have health insurance (61 vs. $76 \%$; $p<0.001$ for all comparisons; table 1). Regarding kidney function and risk factors for kidney disease, those in the lowest versus highest tertile of dietary magnesium intake had higher mean baseline eGFR (100 vs. $\left.94 \mathrm{ml} / \mathrm{min} / 1.73 \mathrm{~m}^{2} ; \mathrm{p}<0.001\right)$ and were less likely to have diabetes ( 11 vs. $18 \%$; $p=0.004$ ). Systolic blood pressure and hypertension status did not differ by tertile of dietary magnesium intake. Participants with lower dietary intake of magnesium also had lower dietary intake of fiber and overall diet quality ( $\mathrm{p}<0.001$ for both comparisons).

Over a median follow-up of 5 years, eGFR was stable in the overall study population on average (mean (SD) eGFR change per year: $0.2 \%(3.6 \%)$ ). However, a total of 177 participants (14.1\% of the total study population) experienced a rapid decline in eGFR ( $23 \%$ per year).

In our unadjusted analysis, participants in the lowest tertile of dietary magnesium intake had $80 \%$ greater odds of rapid eGFR decline (OR for tertile 1 vs. 3: 1.80, 95\% CI $1.22-2.64, \mathrm{p}$ value for trend across tertiles $=0.002$; table 2). The association between dietary intake of magnesium and kidney function decline was similar after adjusting for age, sex, race, education level, health insurance status, poverty status, smoking status and total energy intake in model 2 , and after additionally adjusting for baseline eGFR in model 3. In the fully adjusted model (model 4 ), which was additionally adjusted for hypertension status, diabetes status, $\mathrm{HbAlc}$, body mass index, diet quality and dietary intake of fiber, sodium, calcium, potassium and phosphate, participants in the lowest tertile of dietary magnesium intake had a 2-fold greater odds of rapid decline (OR for tertile 1 vs. 3: $2.02,95 \%$ CI 1.05-3.86, p value for trend across tertiles $=0.02$ ). There was no statistically significant interaction by race, sex, diabetes, hypertension or poverty status on the association between dietary magnesium intake and kidney function decline (all $\mathrm{p}$ values $>0.1$.

\section{Discussion}

In the present study consisting of 1,252 city-dwelling, African-American and Caucasian adult men and women, there were greater odds of rapid decline in kidney function in association with low dietary intake of magnesium. 
Table 1. Baseline characteristics ${ }^{\mathrm{a}}$ of HANDLS study participants by tertile of dietary intake of magnesium

\begin{tabular}{|c|c|c|c|c|}
\hline & tertile 1 (46.9-101.4) & tertile $2(101.4-131.8)$ & tertile $3(131.9-468.2)$ & $\mathrm{p}$ value \\
\hline Age, years & $45.8(8.9)$ & $47.4(9.0)$ & $49.1(9.1)$ & $<0.001$ \\
\hline African-American, n (\%) & $275(65.8)$ & $243(58.3)$ & $196(46.0)$ & $<0.001$ \\
\hline Male, n (\%) & $190(45.5)$ & $187(44.8)$ & $134(32.1)$ & $<0.001$ \\
\hline Poverty status, n (\%) & $183(43.8)$ & $178(42.7)$ & $112(26.9)$ & $<0.001$ \\
\hline Smoking status, $\mathrm{n}(\%)$ & & & & $<0.001$ \\
\hline Never smoker & $121(28.9)$ & $143(34.3)$ & $182(43.6)$ & \\
\hline Former smoker & $60(14.4)$ & $82(19.7)$ & $119(28.5)$ & \\
\hline Current smoker & $237(56.7)$ & $192(46.0)$ & $116(27.8)$ & \\
\hline Hypertension, n (\%) & $69(16.5)$ & $63(15.1)$ & $67(16.1)$ & 0.85 \\
\hline Systolic blood pressure, $\mathrm{mm} \mathrm{Hg}$ & $119.1(18.7)$ & $119.3(19.2)$ & $119.4(19.3)$ & 0.98 \\
\hline Diuretic use, n (\%) & $19(4.5)$ & $32(7.7)$ & $32(7.7)$ & 0.11 \\
\hline Body mass index, $\mathrm{kg} / \mathrm{m}^{2}$ & $29.3(7.4)$ & $30.0(7.4)$ & $30.5(8.1)$ & 0.06 \\
\hline Dietary fiber, $\mathrm{g} / 1,000 \mathrm{kcal}^{\mathrm{b}}$ & $4.1(3.3-5.2)$ & $5.6(4.4-6.9)$ & $8.3(6.2-10.9)$ & $<0.001$ \\
\hline Dietary sodium, mg/1,000 kcal & $1,516(383)$ & $1,619(424)$ & $1,642(524)$ & $<0.001$ \\
\hline Diet quality score ${ }^{\mathrm{c}}$ & $35.2(7.4)$ & $41.2(8.3)$ & $52.8(12.1)$ & $<0.001$ \\
\hline
\end{tabular}

$\mathrm{CAD}=$ Coronary artery disease.

${ }^{a}$ Mean (SD) for continuous variables and n (\%) for categorical variable, unless otherwise stated.

${ }^{\mathrm{b}}$ Median (25th-75th percentile).

${ }^{c}$ Diet quality was assessed using the Healthy Eating Index-2010.

The association persisted even after accounting for sociodemographic characteristics, poverty status, established kidney disease risk factors, comorbidities, baseline kidney function, total energy intake, diet quality and dietary intake of fiber and other micronutrients. The study findings were consistent across important subgroups of the population defined by race, sex, diabetes status, hypertension status and poverty status.

In this study, dietary intake of magnesium was associated with rapid kidney function decline independent of multiple kidney disease risk factors. Similarly, in the Tehran Lipid and Glucose Study consisting of 1,692 Iranian adults without CKD at baseline, those participants in the highest quintile of magnesium intake had a decreased risk of CKD, defined as eGFR $<60 \mathrm{ml} / \mathrm{min} / 1.73 \mathrm{~m}^{2}$, over 3.6 years of follow-up (OR 0.41, 95\% CI 0.22-0.76; p value for trend across quintiles $=0.002$ ) after adjusting for age, sex, energy intake, serum triglycerides, serum cholesterol, body mass index, hypertension, diabetes, physical activ-
Table 2. Odds ${ }^{\mathrm{a}}$ of rapid kidney function decline ( $\geq 3 \%$ eGFR decline/year) by tertile of dietary intake of magnesium

\begin{tabular}{|c|c|c|c|c|}
\hline \multirow[t]{2}{*}{ Model } & \multicolumn{3}{|c|}{ Tertile of dietary intake of magnesium } & \multirow{2}{*}{$\begin{array}{l}\mathrm{p} \text { value } \\
\text { for trend }\end{array}$} \\
\hline & tertile 1 & tertile 2 & tertile 3 & \\
\hline
\end{tabular}

Model $11.80(1.22-2.64) 1.05(0.69-1.60) \quad 1$ (reference) 0.002 Model $21.83(1.20-2.81) 1.04(0.67-1.61) \quad 1$ (reference) 0.003 Model $31.80(1.17-2.77) 1.05(0.68-1.64) \quad 1$ (reference) 0.005 Model $4 \quad 2.02(1.05-3.86) \quad 1.07(0.62-1.84) \quad 1$ (reference) 0.02

a ORs (95\% CIs).

Model 1: unadjusted.

Model 2: adjusted for age, sex, race, education level, health insurance status, poverty status, smoking status and total energy intake.

Model 3: model 2 + baseline eGFR.

Model 4: model 3 + hypertension status, diabetes status, body mass index, HbA1c, diet quality score (Healthy Eating Index-2010) and dietary intake of fiber, sodium, calcium, potassium and phosphate. 
ity and smoking [26]. In the Tehran Lipid and Glucose Study, dietary intake was assessed via a food frequency questionnaire. A stronger association was observed, which may in part be due to a larger difference in quintiles of dietary intake of magnesium relative to the tertiles of dietary intake of magnesium in the present study.

Our findings are supported by previous research demonstrating that other dietary patterns inclusive of magnesium are predictive of kidney disease risk. For instance, magnesium is a component of the equation for potential renal acid load, a measure of dietary acid load [27]. The level of dietary acid load has been reported to be associated with markers of kidney disease in several studies of US adults [11,28-31]. Similarly, high intake of magnesium was one of the key nutrient targets of the DASH diet and the DASH diet with reduced sodium, according to the design of the original trials [32-34]. The DASH diet is low in dietary acid load, and several recent studies have shown that following a DASH-style diet is significantly associated with kidney health $[12,13$, $31,35,36]$. Also, nuts and legumes are 2 rich sources of magnesium, and their higher consumption, along with other vegetable sources of protein, may protect against the development of kidney disease possibly by favorably altering mineral metabolism [11, 14, 37]. Finally, magnesium may simply be a proxy for other kidney-protective dietary components that have not been fully elucidated.

There are several potential pathophysiologic mechanisms through which low dietary intake of magnesium could accelerate the loss of kidney function $[38,39]$. There is extensive research demonstrating that low blood levels of magnesium, which in part is influenced by dietary intake, can lead to an inflammatory, atherogenic and thrombotic response in the vasculature [40-43]. Endothelial cells, layers of which form the endothelial lining of the vasculature, express a magnesium transporter (TRPM7) [44]. Low circulating levels of magnesium may lead to endothelial dysfunction through upregulation of this transporter $[44,45]$. Furthermore, hypomagnesemia may impair the healing process following vascular injury by regulating endothelial cell migration and proliferation [46]. Low magnesium level in the blood has repeatedly been shown to promote vascular calcification $[47,48]$. Furthermore, higher intake of magnesium through oral supplementation may reduce blood pressure levels, which is an established risk factor for kidney disease [49].

It is worth mentioning the major strengths and limitations of our study. The prospective study design allows us to demonstrate a temporal relationship between di- etary intake and kidney function decline. Reverse causality is unlikely since we were able to restrict the analysis to those participants with normal kidney function at baseline (eGFR $\geq 60 \mathrm{ml} / \mathrm{min} / 1.73 \mathrm{~m}^{2}$ ) and there was no statistical evidence of effect modification by diabetes or hypertension status. As is the case with any observational study, there is the possibility that residual confounding could, in part, explain the observed association due to imprecise measurement or lack of measurement of confounding factors. However, we were able to adjust for a number of known risk factors for kidney disease, sociodemographic characteristics, baseline kidney function and relevant dietary factors. In addition, we accounted for several comorbid conditions (hypertension, diabetes, body mass index), which could be considered potential mediators of the association between dietary intake and kidney function decline. Use of self-reported data for dietary assessment could introduce measurement error and bias into the study $[50,51]$. In the present study, we used the average of values from two 24-hour dietary using the AMPM administered by trained interviewers. This dietary assessment instrument has previously been shown to provide accurate estimates of intake of calories and nutrients as well as to represent frequently consumed foods [17-19]. Given the short time frame for which participants are asked to recount food consumption (24 h), recall bias is unlikely. Another limitation is that we were only able to derive estimates of magnesium consumption based on food intake. We did not have access to data on use of magnesium supplements or multi-vitamins. Therefore, the absolute level of magnesium intake may be underestimated in our study. We are only able to assess kidney disease risk within the observed range of dietary intake of magnesium in our study population. It may be warranted to conduct a similar analysis in a population with a wider range of magnesium intake, and with higher levels of magnesium intake in particular. Lastly, the HANDLS study consists of a relatively large sample of an under-studied group: socioeconomically diverse, but primarily low-income, urban population. HANDLS study participants were recruited from a single US city. The analytic sample differed from those who were excluded (due to missing data) on the basis of sex, health insurance status and smoking status; thus, the analytic sample may not be representative of the overall HANDLS study population. Replication in other cohorts would lend further credence to these findings and allow for broader generalizability.

In summary, the lowest tertile of dietary intake of magnesium was significantly associated with approxi- 
mately 2 -fold greater odds of rapid kidney function decline independent of sociodemographics, kidney disease risk factors, baseline eGFR and dietary factors in the HANDLS study. It may be warranted to assess risk of kidney disease incidence or progression in clinical trials of dietary supplementation with magnesium or other diet interventions related to magnesium intake for individuals with low dietary intake of magnesium. Given ours, and other recent reports, clinical guideline bodies might consider evaluating the overall evidence on renal protective diets for the preservation of kidney function.

\section{Acknowledgments}

This research was supported by the Intramural Research Program of the National Institute on Aging, National Institutes of Health. Dr. Deidra C. Crews is supported by grant K23 DK097184 from the National Institute of Diabetes and Digestive and Kidney Diseases. Dr. Casey M. Rebholz is supported by grant K01 DK107782 from the National Institute of Diabetes and Digestive and Kidney Diseases.

\section{Disclosure Statement}

The authors have no relevant conflicts of interest to report.

\section{References}

1 United States Renal Data System: USRDS 2013 Annual Data Report: Atlas of Chronic Kidney Disease and End-Stage Renal Disease in the United States. Bethesda, National Institutes of Health, National Institute of Diabetes and Digestive and Kidney Diseases, 2013.

2 Coresh J, Selvin E, Stevens LA, Manzi J, Kusek JW, Eggers P, Van Lente F, Levey AS: Prevalence of chronic kidney disease in the United States. JAMA 2007;298:2038-2047.

3 Sarnak MJ, Levey AS, Schoolwerth AC, Coresh J, Culleton B, Hamm LL, McCullough PA, Kasiske BL, Kelepouris E, Klag MJ, Parfrey P, Pfeffer M, Raij L, Spinosa DJ, Wilson PW; American Heart Association Councils on Kidney in Cardiovascular Disease, High Blood Pressure Research, Clinical Cardiology, and Epidemiology and Prevention: Kidney disease as a risk factor for development of cardiovascular disease: a statement from the American Heart Association Councils on Kidney in Cardiovascular Disease, High Blood Pressure Research, Clinical Cardiology, and Epidemiology and Prevention. Circulation 2003; 108:2154-2169.

4 Tonelli M, Wiebe N, Culleton B, House A, Rabbat C, Fok M, McAlister F, Garg AX: Chronic kidney disease and mortality risk: a systematic review. J Am Soc Nephrol 2006; 17: 2034-2047.

5 KDIGO: KDIGO 2012 Clinical Practice Guideline for the Evaluation and Management of Chronic Kidney Disease. Kidney Int Suppl 2013;3:1-150.

6 Tin A, Grams ME, Maruthur NM, Astor BC, Couper D, Mosley TH, Selvin E, Coresh J, Kao WH: Results from the atherosclerosis risk in communities study suggest that low serum magnesium is associated with incident kidney disease. Kidney Int 2015;87: 820-827.

7 Joosten MM, Gansevoort RT, Bakker SJ; PREVEND Study Group: Low plasma magnesium and risk of developing chronic kidney disease: results from the PREVEND Study. Kidney Int 2015;87:1262-1263.

8 Lacson E Jr, Wang W, Ma L, Passlick-Deetjen $\mathrm{J}$ : Serum magnesium and mortality in hemodialysis patients in the United States: a cohort study. Am J Kidney Dis 2015;66:10561066.

9 Sakaguchi Y, Shoji T, Hayashi T, Suzuki A, Shimizu M, Mitsumoto K, Kawabata H, Niihata K, Okada N, Isaka Y, Rakugi H, Tsubakihara Y: Hypomagnesemia in type 2 diabetic nephropathy: a novel predictor of end-stage renal disease. Diabetes Care 2012;35:15911597.

10 Van Laecke S, Nagler EV, Verbeke F, Van Biesen W, Vanholder R: Hypomagnesemia and the risk of death and GFR decline in chronic kidney disease. Am J Med 2013;126:825-831.

11 Rebholz CM, Coresh J, Grams ME, Steffen LM, Anderson CA, Appel LJ, Crews DC: Dietary acid load and incident chronic kidney disease: results from the ARIC Study. Am J Nephrol 2015;42:427-435.

12 Lin J, Fung TT, Hu FB, Curhan GC: Association of dietary patterns with albuminuria and kidney function decline in older white women: a subgroup analysis from the Nurses' Health Study. Am J Kidney Dis 2011;57:245254.

13 Crews DC, Kuczmarski MF, Miller ER 3rd, Zonderman AB, Evans MK, Powe NR: Dietary habits, poverty, and chronic kidney disease in an urban population. J Ren Nutr 2015; 25:103-110.

14 Scialla JJ, Appel LJ, Wolf M, Yang W, Zhang $\mathrm{X}$, Sozio SM, Miller ER 3rd, Bazzano LA, Cuevas M, Glenn MJ, Lustigova E, Kallem RR, Porter AC, Townsend RR, Weir MR, Anderson CA; Chronic Renal Insufficiency CohortCRIC Study Group: Plant protein intake is associated with fibroblast growth factor 23 and serum bicarbonate levels in patients with chronic kidney disease: the Chronic Renal Insufficiency Cohort study. J Ren Nutr 2012;22: 379-388.e1.
15 Evans MK, Lepkowski JM, Powe NR, LaVeist T, Kuczmarski MF, Zonderman AB: Healthy aging in neighborhoods of diversity across the life span (HANDLS): overcoming barriers to implementing a longitudinal, epidemiologic, urban study of health, race, and socioeconomic status. Ethn Dis 2010;20:267275.

16 Myers GL, Miller WG, Coresh J, Fleming J, Greenberg N, Greene T, Hostetter T, Levey AS, Panteghini M, Welch M, Eckfeldt JH; National Kidney Disease Education Program Laboratory Working Group: Recommendations for improving serum creatinine measurement: a report from the Laboratory Working Group of the National Kidney Disease Education Program. Clin Chem 2006;52: 5-18.

17 Blanton CA, Moshfegh AJ, Baer DJ, Kretsch MJ: The USDA automated multiple-pass method accurately estimates group total energy and nutrient intake. J Nutr 2006; 136 : 2594-2599.

18 Rumpler WV, Kramer M, Rhodes DG, Moshfegh AJ, Paul DR: Identifying sources of reporting error using measured food intake. Eur J Clin Nutr 2008;62:544-552.

19 Moshfegh AJ, Rhodes DG, Baer DJ, Murayi T, Clemens JC, Rumpler WV, Paul DR, Sebastian RS, Kuczynski KJ, Ingwersen LA, Staples RC, Cleveland LE: The US Department of Agriculture Automated Multiple-Pass Method reduces bias in the collection of energy intakes. Am J Clin Nutr 2008;88:324332

20 Food and Nutrition Board, Institute of Medicine: Dietary Reference Intakes: Calcium, Phosphorus, Magnesium, Vitamin D, and Fluoride. Washington, National Academy Press, 1997.

21 Guenther PM, Casavale KO, Reedy J, Kirkpatrick SI, Hiza HA, Kuczynski KJ, Kahle LL, Krebs-Smith SM: Update of the healthy eating index: HEI-2010. J Acad Nutr Diet 2013;113: 569-580. 
22 Levey AS, Stevens LA, Schmid CH, Zhang YL, Castro AF 3rd, Feldman HI, Kusek JW, Eggers P, Van Lente F, Greene T, Coresh J; CKDEPI (Chronic Kidney Disease Epidemiology Collaboration): A new equation to estimate glomerular filtration rate. Ann Intern Med 2009;150:604-612.

23 Peralta CA, Vittinghoff E, Bansal N, Jacobs D Jr, Muntner P, Kestenbaum B, Lewis C, Siscovick D, Kramer H, Shlipak M, Bibbins-Domingo K: Trajectories of kidney function decline in young black and white adults with preserved GFR: results from the Coronary Artery Risk Development in Young Adults (CARDIA) study. Am J Kidney Dis 2013;62:261-266.

24 Bansal N, Lin F, Vittinghoff E, Peralta C, Lima J, Kramer H, Shlipak M, Bibbins-Domingo K: Estimated GFR and subsequent higher left ventricular mass in young and middle-aged adults with normal kidney function: the Coronary Artery Risk Development in Young Adults (CARDIA) Study. Am J Kidney Dis 2016;67:227-234.

25 US Census Bureau, Social, Economic, and Housing Statistics Division. Poverty Thresholds, 2004. http://www.census.gov/data/ tables/time-series/demo/income-poverty/ historical-poverty-thresholds.html (accessed July 14, 2016).

26 Farhadnejad H, Asghari G, Mirmiran P, Yuzbashian E, Azizi F: Micronutrient intakes and incidence of chronic kidney disease in adults: Tehran Lipid and Glucose Study. Nutrients 2016;8:217.

27 Remer T, Manz F: Potential renal acid load of foods and its influence on urine $\mathrm{pH}$. J Am Diet Assoc 1995;95:791-797.

28 Scialla JJ, Appel LJ, Astor BC, Miller ER 3rd, Beddhu S, Woodward M, Parekh RS, Anderson CA; African American Study of Kidney Disease and Hypertension Study Group: Net endogenous acid production is associated with a faster decline in GFR in African Americans. Kidney Int 2012;82:106-112.

29 Banerjee T, Crews DC, Wesson DE, Tilea A, Saran R, Rios Burrows N, Williams DE, Powe NR; Centers for Disease Control and Prevention Chronic Kidney Disease Surveillance Team: Dietary acid load and chronic kidney disease among adults in the United States. BMC Nephrol 2014;15:137.

30 Banerjee T, Crews DC, Wesson DE, Tilea AM, Saran R, Ríos-Burrows N, Williams DE, Powe NR; Centers for Disease Control and Prevention Chronic Kidney Disease Surveillance Team: High dietary acid load predicts ESRD among adults with CKD. J Am Soc Nephrol 2015;26:1693-1700.
31 Scialla JJ, Anderson CA: Dietary acid load: a novel nutritional target in chronic kidney disease? Adv Chronic Kidney Dis 2013;20:141149.

32 Appel LJ, Moore TJ, Obarzanek E, Vollmer WM, Svetkey LP, Sacks FM, Bray GA, Vogt TM, Cutler JA, Windhauser MM, Lin PH, Karanja N: A clinical trial of the effects of dietary patterns on blood pressure. DASH Collaborative Research Group. N Engl J Med 1997;336:1117-1124.

33 Vogt TM, Appel LJ, Obarzanek E, Moore TJ, Vollmer WM, Svetkey LP, Sacks FM, Bray GA, Cutler JA, Windhauser MM, Lin PH, Karanja NM: Dietary approaches to stop hypertension: rationale, design, and methods. DASH Collaborative Research Group. J Am Diet Assoc 1999;99(8 suppl):S12-S18.

34 Sacks FM, Svetkey LP, Vollmer WM, Appel LJ, Bray GA, Harsha D, Obarzanek E, Conlin PR, Miller ER 3rd, Simons-Morton DG, Karanja $\mathrm{N}$, Lin PH; DASH-Sodium Collaborative Research Group: Effects on blood pressure of reduced dietary sodium and the dietary approaches to stop hypertension (DASH) diet. DASH-Sodium Collaborative Research Group. N Engl J Med 2001;344:3-10.

35 Svetkey LP, Sacks FM, Obarzanek E, Vollmer WM, Appel LJ, Lin PH, Karanja NM, Harsha DW, Bray GA, Aickin M, Proschan MA, Windhauser MM, Swain JF, McCarron PB, Rhodes DG, Laws RL: The DASH diet, sodium intake and blood pressure trial (DASHsodium): rationale and design. DASH-Sodium Collaborative Research Group. J Am Diet Assoc 1999;99(8 suppl):S96-S104.

36 Rebholz CM, Crews DC, Grams ME, Steffen LM, Levey AS, Miller ER 3rd, Appel LJ, Coresh J: DASH (dietary approaches to stop hypertension) diet and risk of subsequent kidney disease. Am J Kidney Dis 2016;pii:S0272-6386(16)30257-8.

37 US Department of Agriculture, Agricultural Research Service, Nutrient Data Laboratory: USDA National Nutrient Database for Standard Reference, 2015.

38 Spiegel DM: Magnesium in chronic kidney disease: unanswered questions. Blood Purif 2011;31:172-176.

39 Massy ZA, Drüeke TB: Magnesium and cardiovascular complications of chronic kidney disease. Nat Rev Nephrol 2015;11:432-442.

40 Maier JA, Malpuech-Brugère C, Zimowska W, Rayssiguier Y, Mazur A: Low magnesium promotes endothelial cell dysfunction: implications for atherosclerosis, inflammation and thrombosis. Biochim Biophys Acta 2004; 1689:13-21.
41 Ferrè S, Baldoli E, Leidi M, Maier JA: Magnesium deficiency promotes a pro-atherogenic phenotype in cultured human endothelial cells via activation of NFkB. Biochim Biophys Acta 2010;1802:952-958.

42 Van Laecke S, Van Biesen W, Vanholder R Hypomagnesaemia, the kidney and the vessels. Nephrol Dial Transplant 2012;27:40034010.

43 Dong JF, Cruz MA, Aboulfatova K, Martin C, Choi H, Bergeron AL, Martini SR, Kroll MH, Kent TA: Magnesium maintains endothelial integrity, up-regulates proteolysis of ultralarge von Willebrand factor, and reduces platelet aggregation under flow conditions. Thromb Haemost 2008;99:586-593.

44 Baldoli E, Castiglioni S, Maier JA: Regulation and function of TRPM7 in human endothelial cells: TRPM7 as a potential novel regulator of endothelial function. PLoS One 2013; 8:e59891.

45 Zeng Z, Inoue K, Sun H, Leng T, Feng X, Zhu L, Xiong ZG: TRPM7 regulates vascular endothelial cell adhesion and tube formation. Am J Physiol Cell Physiol 2015;308:C308C318.

46 Banai S, Haggroth L, Epstein SE, Casscells W: Influence of extracellular magnesium on capillary endothelial cell proliferation and migration. Circ Res 1990;67:645-650.

47 Salem S, Bruck H, Bahlmann FH, Peter M, Passlick-Deetjen J, Kretschmer A, Steppan S, Volsek M, Kribben A, Nierhaus M, Jankowski V, Zidek W, Jankowski J: Relationship between magnesium and clinical biomarkers on inhibition of vascular calcification. Am J Nephrol 2012;35:31-39.

48 Kircelli F, Peter ME, Sevinc Ok E, Celenk FG Yilmaz M, Steppan S, Asci G, Ok E, PasslickDeetjen J: Magnesium reduces calcification in bovine vascular smooth muscle cells in a dose-dependent manner. Nephrol Dial Transplant 2012;27:514-521.

49 Zhang X, Li Y, Del Gobbo LC, Rosanoff A, Wang J, Zhang W, Song Y: Effects of magnesium supplementation on blood pressure: a meta-analysis of randomized double-blind placebo-controlled trials. Hypertension 2016; 68:324-333.

50 Kipnis V, Midthune D, Freedman L, Bingham S, Day NE, Riboli E, Ferrari P, Carroll RJ: Bias in dietary-report instruments and its implications for nutritional epidemiology. Public Health Nutr 2002;5:915-923.

51 Freedman LS, Schatzkin A, Midthune D, Kipnis V: Dealing with dietary measurement error in nutritional cohort studies. J Natl Cancer Inst 2011;103:1086-1092. 